\title{
Modification of tidal resonance in the Severn Estuary by a barrage and lagoon
}

\author{
Qian $\mathrm{Ma}^{1}{ }^{\mathbb{D}} \cdot$ Thomas A. A. Adcock ${ }^{1}$
}

Received: 18 July 2019 / Accepted: 15 May 2020 / Published online: 9 June 2020

(c) The Author(s) 2020

\begin{abstract}
The Bristol Channel/Severn Estuary has some of the largest tides in the world with a mean spring tidal range of $12.2 \mathrm{~m}$. Numerous proposals have been made to exploit this for energy extraction. However, the large tidal range is partially driven by tidal resonance and such systems can be sensitive to small changes. Thus, it is important to understand the impact of a barrage on the resonance of the system which in turn leads to an understanding of the environmental impact of building a barrage. In this paper, we examine the resonant response of the Bristol Channel system, with and without a barrage structure deployed, using a depth-averaged numerical model. We find that the barrage can alter the response of the Bristol Channel to excitation with higher frequencies than $12 \mathrm{~h}$. However, the barrage causes very little change to the resonant response for longer periods including for the semi-diurnal periods which dominate the tides in the region. We also briefly examine the Swansea Lagoon scheme and find that this is too small to have a significant impact on the resonant response of the channel.
\end{abstract}

Keywords Resonance $\cdot$ Bristol Channel $\cdot$ Severn Estuary

\section{Introduction}

Tidal energy is a clean and predictable, although intermittent source of power. Tidal barrages or lagoons enable a head difference to be built up across tidal turbines as the tide goes in and out. Perhaps the most promising location for the technology is the Severn Estuary/Bristol Channel in Great Britain.

There have been many proposals to build a barrage across the Severn to extract energy from the tide (Bondi 1981; Hendry 2016). The location is suitable for this because of the very large tidal range and proximity to infrastructure and population centres. A more recent proposal has been made for a smaller scale tidal 'lagoon' in Swansea Bay (Waters and Aggidis 2016). This would be primarily a proof of concept project. A key part of the decision making process as to whether to go ahead with such schemes is to appreciate the effect they would have on the tidal hydrodynamics. This is important both in assessing the power output and in determining the environmental change caused by such a structure. This paper focuses on understanding some of

Qian Ma

qian.ma@eng.ox.ac.uk

1 Department of Engineering Science, University of Oxford, Oxford, UK the fundamental science of how the hydrodynamics are modified.

The large tidal range in the Severn Estuary, sometimes described as a hyper-tidal system, is caused partly by the funnel like shape of the estuary and partly by the resonance of the semi-diurnal tidal constituents (Fong and Heaps 1978). The construction of a barrage would modify the hydrodynamics. There would obviously be significant changes to the tidal dynamics in the impounded area and significant local changes on the seaward side of the barrage. However, there may also be larger scale changes. For instance, if there was a significant change to the partial amphidromic point near Dublin this could lead to significantly different water levels and coastal flooding. One driver of such large scale change could be a change in the resonant length and/or the damping of the tidal channel (Neill et al. 2018). Systems which are at resonance can be sensitive to small changes (Arbic et al. 2009; Arbic and Garrett 2010). Thus, in understanding how a Severn Barrage alters the tidal hydrodynamics, and in how a barrage might be designed to affect a particular change, it is necessary to understand the physics.

In this paper, we use a depth-averaged numerical model to simulate the tidal hydrodynamics of the region. Following the approach of Serhadlıoğlu (2014) and Gao and Adcock (2017), we force the model with a range of 
frequencies and examine the response. We do this for the unmodified system as well as for the cases with a Severn Barrage present. We also briefly consider the smaller Swansea Bay scheme.

The study we present here looks explicitly at the resonance phenomenon and how this is modified by the presence of a Severn Barrage. It is not a study of the general impact of these on the hydrodynamics of a Severn Barrage. This has been considered in detail elsewhere (Bourban et al. 2014; Osment et al. 2011; Ward et al. 2012; Xia et al. $2010 \mathrm{~b}$ ) and was considered as part of a wider study by the Authors in Ma et al. (2019b). Our paper helps interpret these other results and contributes to an understanding which informs the design an operating system for such a barrage. Hydrodynamic impacts would only be one environmental consequence of building a barrage [see for instance Kirby and Shaw (2005)].

\section{Tidal resonance}

Tidal constituents are amplified or suppressed depending on how close they are to the natural period of oscillation of the ocean or region of ocean (Godin 1993). Large tides will tend to occur where the natural period is close to that of the semi-diurnal constituents (Pugh 1996). The resonant nature of a tidal system can be examined by field measurements of different tidal constituents and careful comparisons of these with theory (e.g. Garrett 1972; Sutherland et al. 2005).

Various estimates, using different techniques, have been used to examine the resonant nature of the Bristol Channel system. These are summarised in Table 1 . There is clearly some variation in the estimate of the resonant period of the system. However, most estimates suggest that the system has a slightly lower natural period than the semi-diurnal tidal constituents. The present study is, to our knowledge, the first to explicitly consider how resonance is modified by the presence of barrage.

Table 1 Estimates of the fundamental resonance period of the Bristol Channel derived form various theoretical models

\begin{tabular}{|c|c|c|c|}
\hline Model & Simulation & $\begin{array}{l}\text { Fundamen- } \\
\text { tal period } \\
\text { (h) }\end{array}$ & $\omega / \omega_{M_{2}}$ \\
\hline Heath (1981) & $\begin{array}{l}\text { A linear resonance } \\
\text { model }\end{array}$ & $7.3-9.0$ & $1.12-1.15$ \\
\hline Liang et al. (2014) & 1-D numerical model & $8.0-9.0$ & $1.38-1.55$ \\
\hline Serhadlıŏglu (2014) & $\begin{array}{l}\text { 2-D unstructured } \\
\text { model }\end{array}$ & $10.3-11.3$ & $1.10-1.20$ \\
\hline Gao (2017) & $\begin{array}{l}\text { 2-D unstructured } \\
\text { model }\end{array}$ & $8.6-10.0$ & $1.20-1.40$ \\
\hline
\end{tabular}

\section{Methods}

\subsection{Numerical model}

In the present study, we solve the two-dimensional shallow water equations, as shown in Eqs. (1), (2) and (3), that are commonly used for modelling the tide using DG-SWEM (Kubatko et al. 2006; Westerink et al. 2008) which is a discontinuous Galerkin solver within the ADCIRC framework.

$\frac{\partial \xi}{\partial t}+\frac{\partial(D u)}{\partial x}+\frac{\partial(D v)}{\partial y}=0$,

$\frac{\partial u}{\partial t}+v \frac{\partial u}{\partial y}+u \frac{\partial u}{\partial x}-f v=-\frac{\partial \Omega}{\partial x}-\frac{1}{\rho}\left(\frac{\partial P}{\partial x}-\frac{\partial F}{\partial z}\right)$,

$\frac{\partial v}{\partial t}+u \frac{\partial v}{\partial x}+v \frac{\partial v}{\partial y}+f u=-\frac{\partial \Omega}{\partial y}-\frac{1}{\rho}\left(\frac{\partial P}{\partial y}-\frac{\partial G}{\partial z}\right)$

where $u$ and $v$ are depth-averaged horizontal velocities in the $x$ - and $y$-directions; $f=2 \Omega \sin \Phi$ is the Coriolis parameter; $\Omega$ is the angular speed of the earth; $P$ is the atmospheric
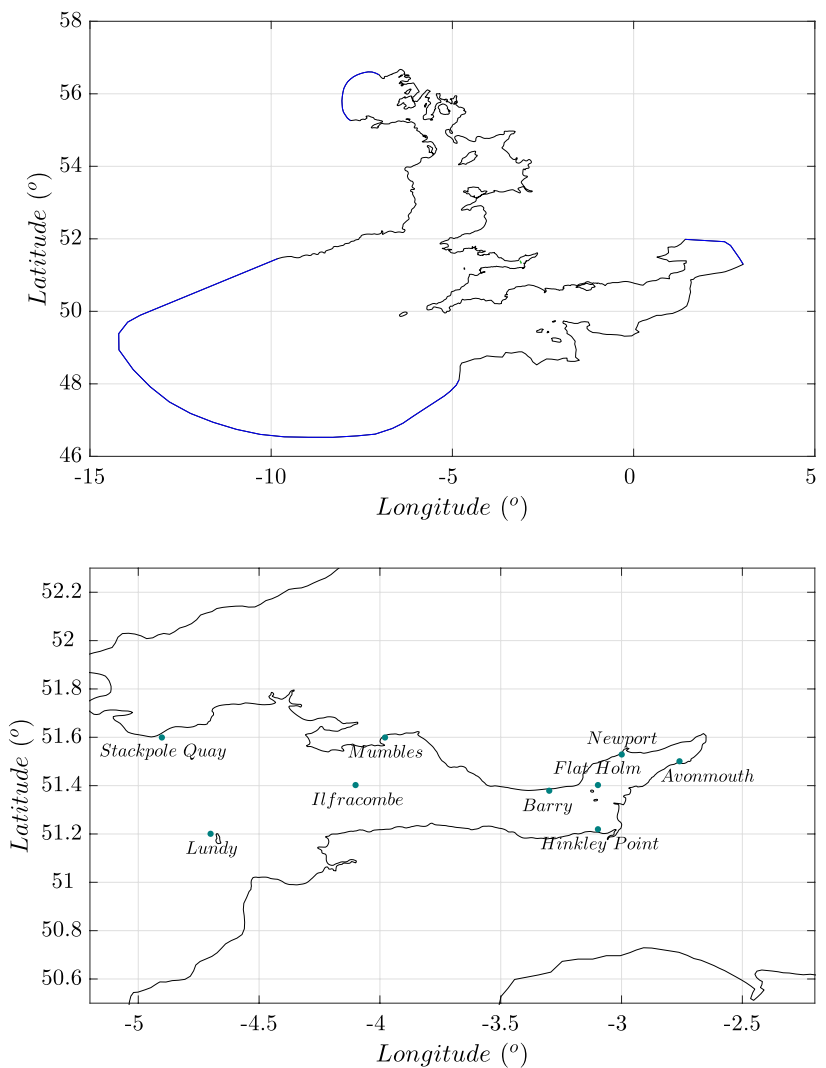

Fig. 1 Model computational details: the model domain, blue lines show the ocean boundaries (top); locations of measurement stations for model validation (bottom) 
pressure; $F$ is the total stress in the positive $x$-direction and $G$ is in the $y$-direction. The numerical model has been extensively used for the analysis of tidal and coastal hydrodynamics (Adcock et al. 2014; Mulamba et al. 2019).

The domain used in the present study is shown in Fig. 1. The model is derived from that of Serhadlıoğlu (2014); Serhadlıoğlu et al. (2013) and her model has been extended to include the English Channel using the model of Adcock and Draper (2014). The mesh has 51,458 nodes with the size of the elements varying from $51 \mathrm{~km}$ near to the continental shelf to $0.4 \mathrm{~km}$ in the Bristol Channel. Serhadlıoğlu (2014) carried out a careful study of mesh independence. The present authors have also checked that there are no significant mesh effects locally around the barrage. Two sets of bathymetry have been used in this study. Both are from SeaZone. In the Bristol Channel itself, high-quality survey data are used. Across the rest of the domain, lower quality data have been employed based on Admiralty Charts. Elevations have been corrected for mean water level. Our experience is that these data sets are very significantly better than the open source GEBCO data commonly used for

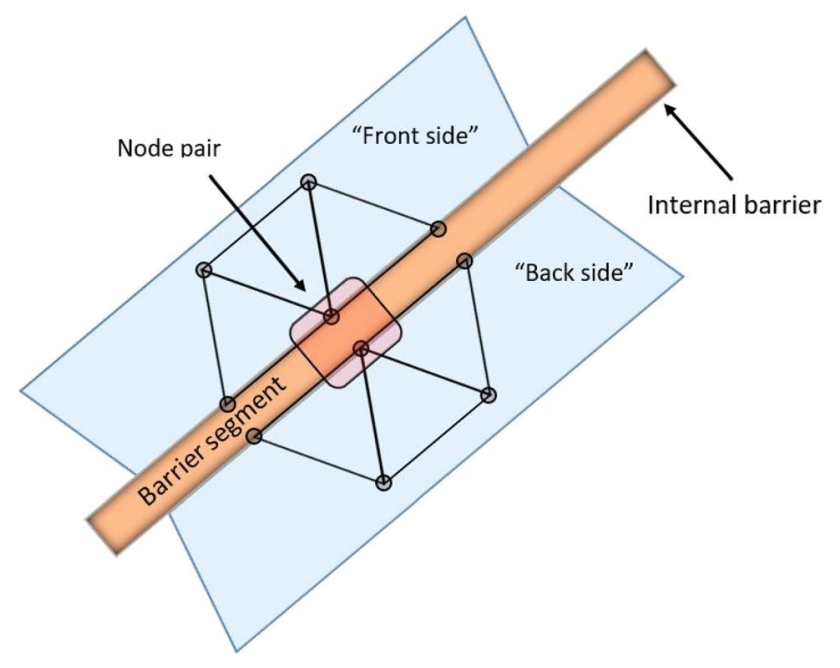

Fig. 2 Top view of internal (barrage) barrier and triangular element representation (from: Ma et al. 2019a)

Table 2 Specifications of the Severn Barrage and the Swansea Lagoon considered

\begin{tabular}{lll}
\hline & $\begin{array}{l}\text { Severn Barrage } \\
\text { design }\end{array}$ & $\begin{array}{l}\text { Swansea } \\
\text { Lagoon } \\
\text { design }\end{array}$ \\
\hline No. of turbines & 216 & 16 \\
Turbine capacity $(\mathrm{MW})$ & 40 & 20 \\
Turbine diameter $(\mathrm{m})$ & 9.0 & 7.35 \\
Sluice area $\left(\mathrm{m}^{2}\right)$ & 35,000 & 800 \\
Barrage length $(\mathrm{km})$ & 16.1 & 9.5 \\
\hline
\end{tabular}

such studies. Wetting and drying is implemented following Bunya et al. (2009) and used to model the inter-tidal zones within the large model domain. The bed friction has been tuned in the previous studies by comparison with field data. A uniform bed friction coefficient, $C_{\mathrm{d}}$ of 0.0025 is applied where $C_{\mathrm{d}}=F / \rho A u|u|$. The validation studies found this
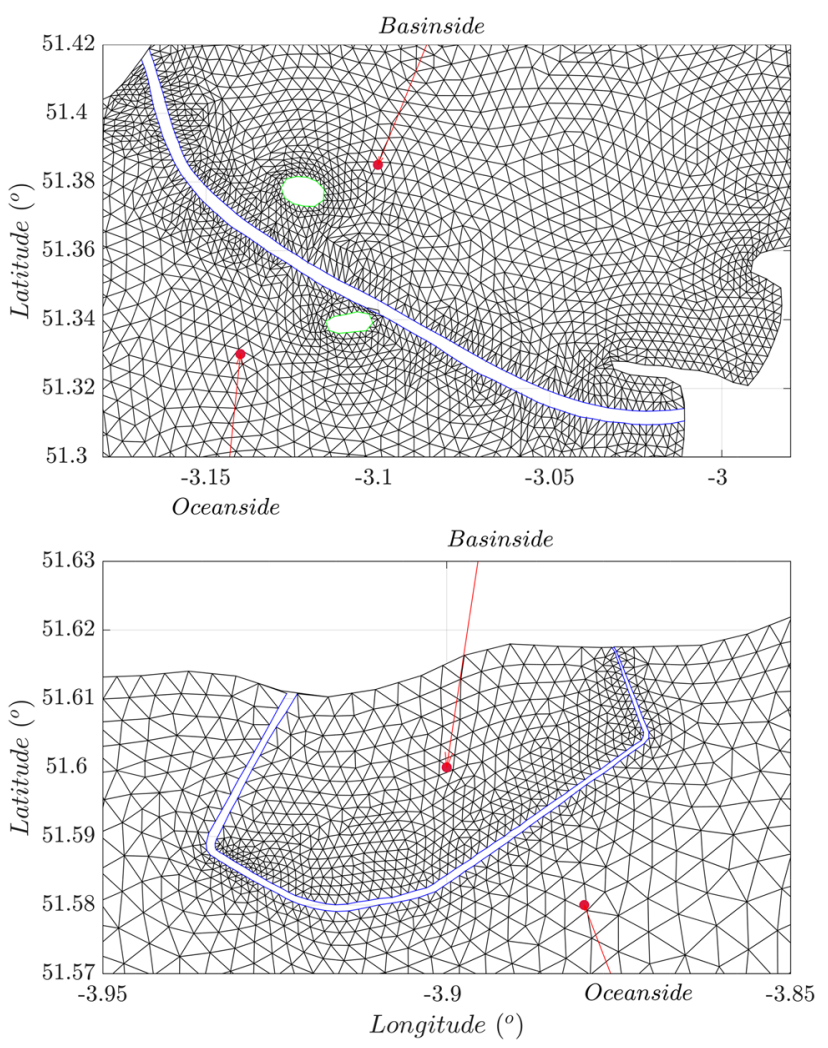

Fig. 3 Numerical mesh details of the barrage and lagoon layout: Severn Barrage (top); Swansea Lagoon (bottom). The blue lines indicate the barrage and lagoon boundaries as shown (colour figure online)

Table 3 Harmonic analysis of $M_{2}$ tidal elevation amplitudes and phases at different stations within and beyond the Bristol Channel

\begin{tabular}{llllll}
\hline Station & \multicolumn{2}{l}{$M_{2}$ Amplitude $(\mathrm{m})$} & & \multicolumn{2}{c}{$M_{2}$ Phase $\left(^{\circ}\right)$} \\
\cline { 2 - 3 } \cline { 5 - 6 } \cline { 5 - 6 } & Observations & Predictions & & Observations & Predictions \\
\hline $\begin{array}{l}\text { Stackpole } \\
\quad 2.51\end{array}$ & 2.54 & 168 & 174 \\
$\quad$ Muay & & & & \\
Barry & 3.82 & 3.91 & 185 & 183 \\
Flat Holm & 3.90 & 4.02 & 190 & 188 \\
Avonmouth & 4.22 & 4.39 & 201 & 182 \\
Hinkley & 3.80 & 3.97 & 185 & 184 \\
$\quad$ Point & & & & 167 \\
Ilfracombe & 3.04 & 3.01 & 162 & 167 \\
Lundy & 2.67 & 2.56 & 160 & 165 \\
\hline
\end{tabular}

Locations of the measurement stations shown in Fig. 1 

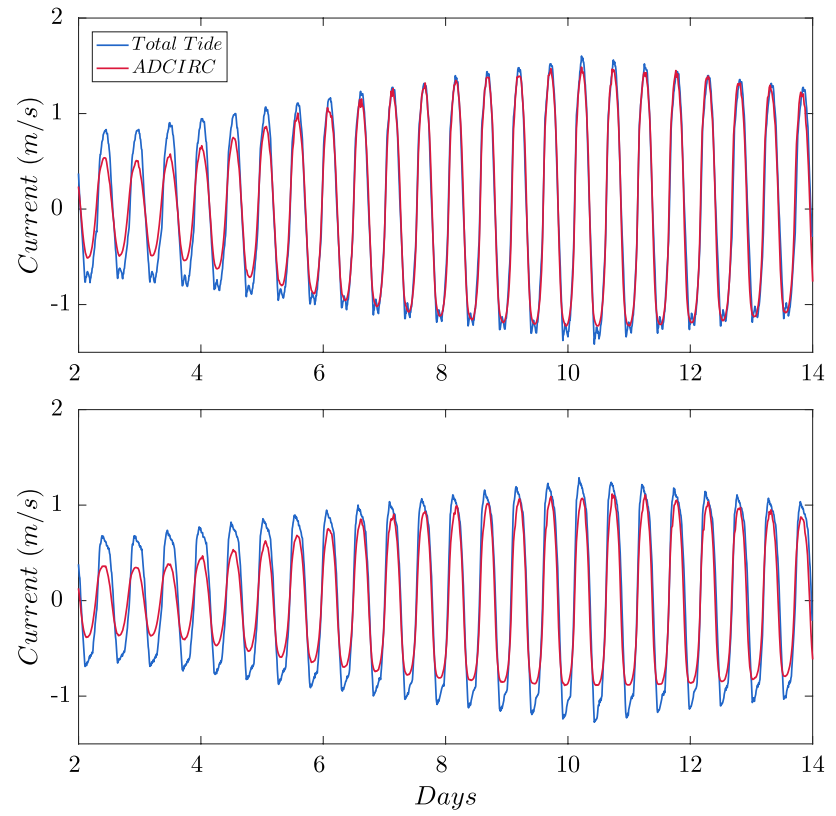

Fig. 4 Predicted tidal current magnitude time histories at Flat Holm, $51^{\circ} 23.23^{\prime} \mathrm{N} 3^{\circ} 05.07^{\prime} \mathrm{W}$, using DG-ADCIRC and Total tide: north/ south direction (top); east/west direction (bottom)
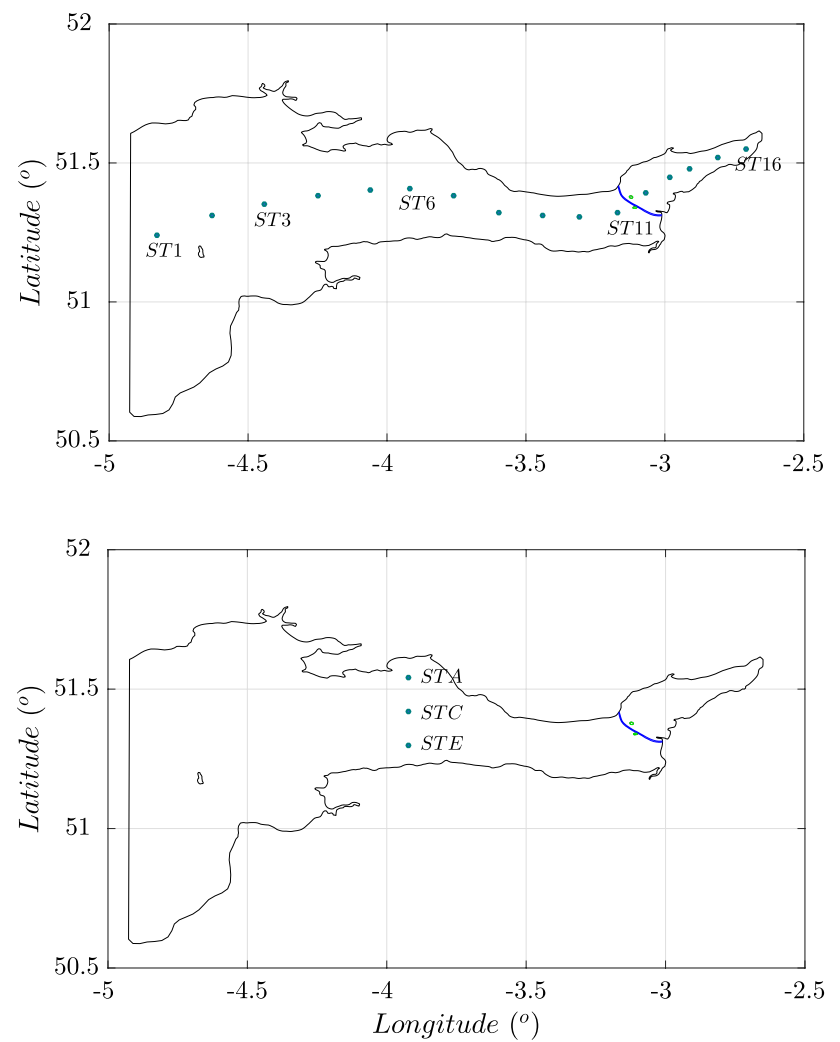

Fig. 5 Resonance response measurement stations: stations along the channel (top); stations across the channel (bottom). Blue line indicates the purposed barrage location (colour figure online) value to give best agreement with measurement. We note that Gao and Adcock (2017) found the frequency of the resonant peaks in the channel varied slightly with different bed friction values [see also Cui et al. (2019)].

Details and verification of how the barrage is implemented within the model is given in Schnabl et al. (2019). The barrage is represented as an internal barrier within the model. The flow between turbines and sluices is modelled as a subgrid scale process with the flow passing between nodes on either side of the barrage as shown in Fig. 2. The properties of the barrage and lagoon we have modelled are given in Table 2. The exact operating strategy is varied and given below where appropriate. In all cases, we consider two-way generation.

The numerical mesh requires some remeshing to allow for the inclusion of the barrage structure. The mesh around the Severn Barrage and Swansea Lagoon are shown in Fig. 3.

\subsection{Validation of model}

The model used has been compared with field data in a number of previous studies (Gao 2017; Serhadlıoğlu 2014). For this reason, in the present paper, we only briefly present a comparison with field data as this does not differ significantly from that in the literature.

Table 3 shows a comparison between modelled and observed water levels from tide table for the $M_{2}$ tidal constituent. Agreement is generally acceptable. For brevity we do not present results for $S_{2}$ or $K_{1}$ here but the results are similar to those for $M_{2}$. Figure 4 presents a comparison between observed currents from the Admiralty's TotalTide software and model predictions. Current magnitude is difficult to get correct in such models as it often varies over small spatial scales. As such, more weight should be given to the phase of the current which is dependent on the balance between inertia and drag forces [see Adcock et al. (2013)]. Again agreement is considered acceptable although it does appear that there is some mismatch associated with the $S_{2}$ constituent of current.

\subsection{Methodology for studying resonance}

To examine the resonance of the system, we follow the approach of Gao and Adcock (2017) and Serhadlıoğlu (2014). We start by running our model by forcing it simply with an $M_{2}$ tide. We then vary the period of the tidal forcing to examine how the amplitude of the response varies depending upon the input frequency.

To examine the unmodified response, we also use an alternative approach. We run the model without tidal forcing but perturb it before removing the disturbance and observing the subsequent unforced response. Essentially this is equivalent to a 'hammer test' commonly performed on mechanical 
systems. Thus, we perturb the system from equilibrium and then allow it to oscillate freely. This is simply an alternative approach for examining the naturally occurring resonances in the system. The model is perturbed by applying a 'wind' shear force to part or all of the domain.

\section{Unmodified resonance response}

We start by considering the resonant response of the Bristol Channel in its natural state without artificial tidal energy extraction. The model is driven by the tides with a range of frequencies. Our results for this are very similar to those presented in Serhadlıoglu (2014) who used the same method. The different stations used in this study are shown in Fig. 5. Figure 6 presents the amplitude of the tide at different stations along the channel, across the channel and the ratio of the amplitude at the end, middle and top of the channel for different frequencies. Figure 7 presents the co-tidal charts for $0.5 M_{2}, 0.8 M_{2}, M_{2}, 2 M_{2}, 3 M_{2}$ and $4 M_{2}$ over the whole model domain. These show different areas resonate with different frequencies. The response of areas far from the Bristol Channel is primarily driven by local resonances rather than the change in the dynamics of the Bristol Channel itself.

To analyse the natural case further, we consider the free response of the system when all forcing is removed. We do this by applying a force equivalent to a wind from the west for 2 days. This produces an increase in the water level in the estuary (with a hydrostatic pressure gradient to balance this steady force). The model is then left to oscillate. This response is shown in Fig. 8. We analyse the frequency content of the time series after day 10 of the simulation using a standard Fourier approach.

Both analysis methods show reasonably consistent results. The first peak is at $\sim 1.2 \omega / \omega_{M_{2}}$. The second peak is at a slightly different frequency in the two approaches being at $\sim 1.8 \omega / \omega_{M_{2}}$ using the forced approach and $\sim 1.6 \omega / \omega_{M_{2}}$ in the free oscillation approach. We assume these are generated by the same underlying phenomenon but cannot account for the apparent difference in frequency. There are some small resonances at much higher frequencies but these are well away from the semi-diurnal or diurnal forcing and we do not consider these further.

We also consider extra simulations for the free oscillation approach where the forcing is just applied to the Bristol Channel part of the domain and also where a much lower bed friction is used (the minimum friction necessary for model stability). Note that friction will be much more significant in the shallow water Bristol Channel than in the deeper Celtic Sea. In both these cases the second peak $\left(\sim 1.6 \omega / \omega_{M_{2}}\right)$ is amplified relative to the first peak $\left(\sim 1.2 \omega / \omega_{M_{2}}\right)$. From this and other evidence, including the results below when a barrage is added to the model, we conclude the following.
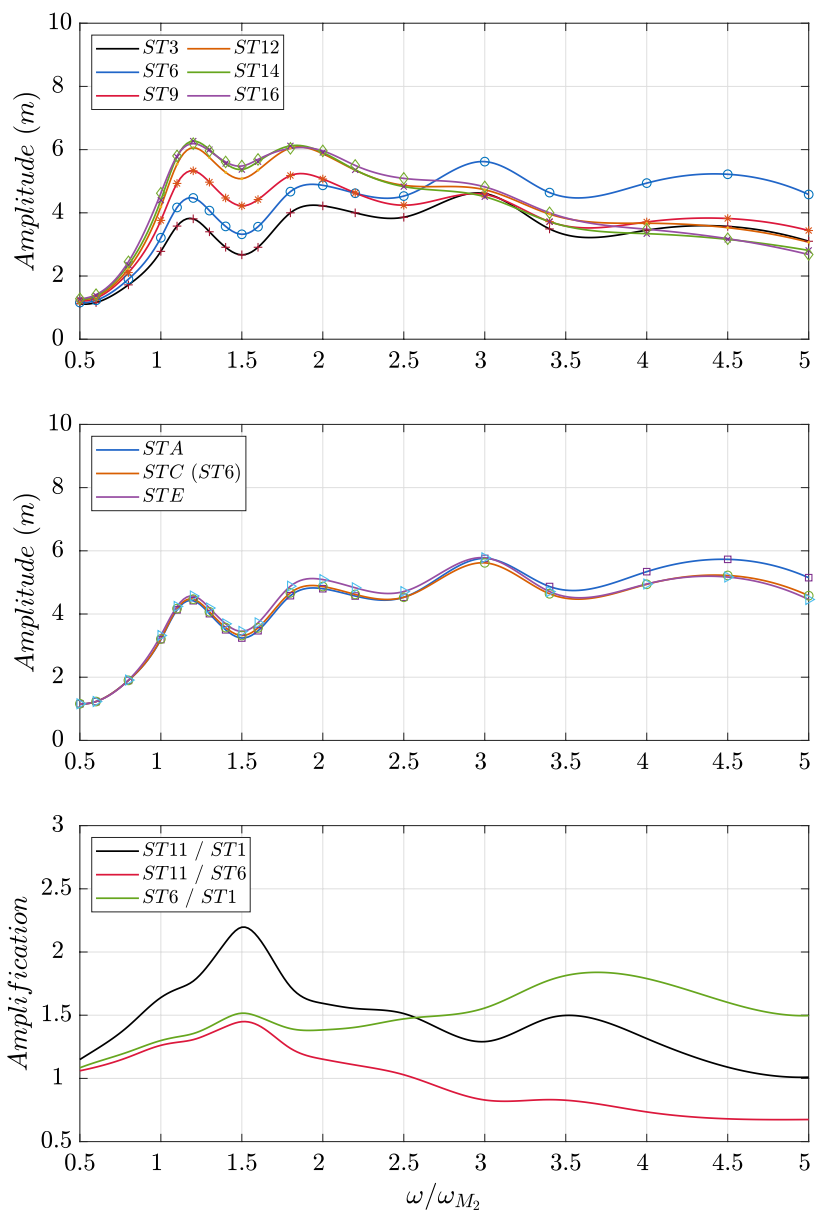

Fig. 6 Resonance responses for the case without a barrage: Responses results along the channel (top); responses results across the channel (middle); amplification of the response (bottom)

The first peak $\left(\sim 1.2 \omega / \omega_{M_{2}}\right)$ appears to be due to the combined Celtic Sea and Bristol Channel system. The higher frequency resonance appears to be a resonance within the Channel itself.

\section{Resonance response of modified system}

\subsection{Response to Severn Barrage}

We now examine the response of the Bristol Channel to different frequencies when a tidal barrage is present. We consider three operating strategies. Two different operational modes are considered where different starting heads [see Baker (1991), Prandle (1984)] are used. Case A has a starting head of $1.5 \mathrm{~m}$ and Case B one of $4 \mathrm{~m}$. We also consider the extreme case where the barrage is completely closed as a limiting case [although such a scenario might happen if the barrage was used for flood protection (Ma et al. 2019b)]. 

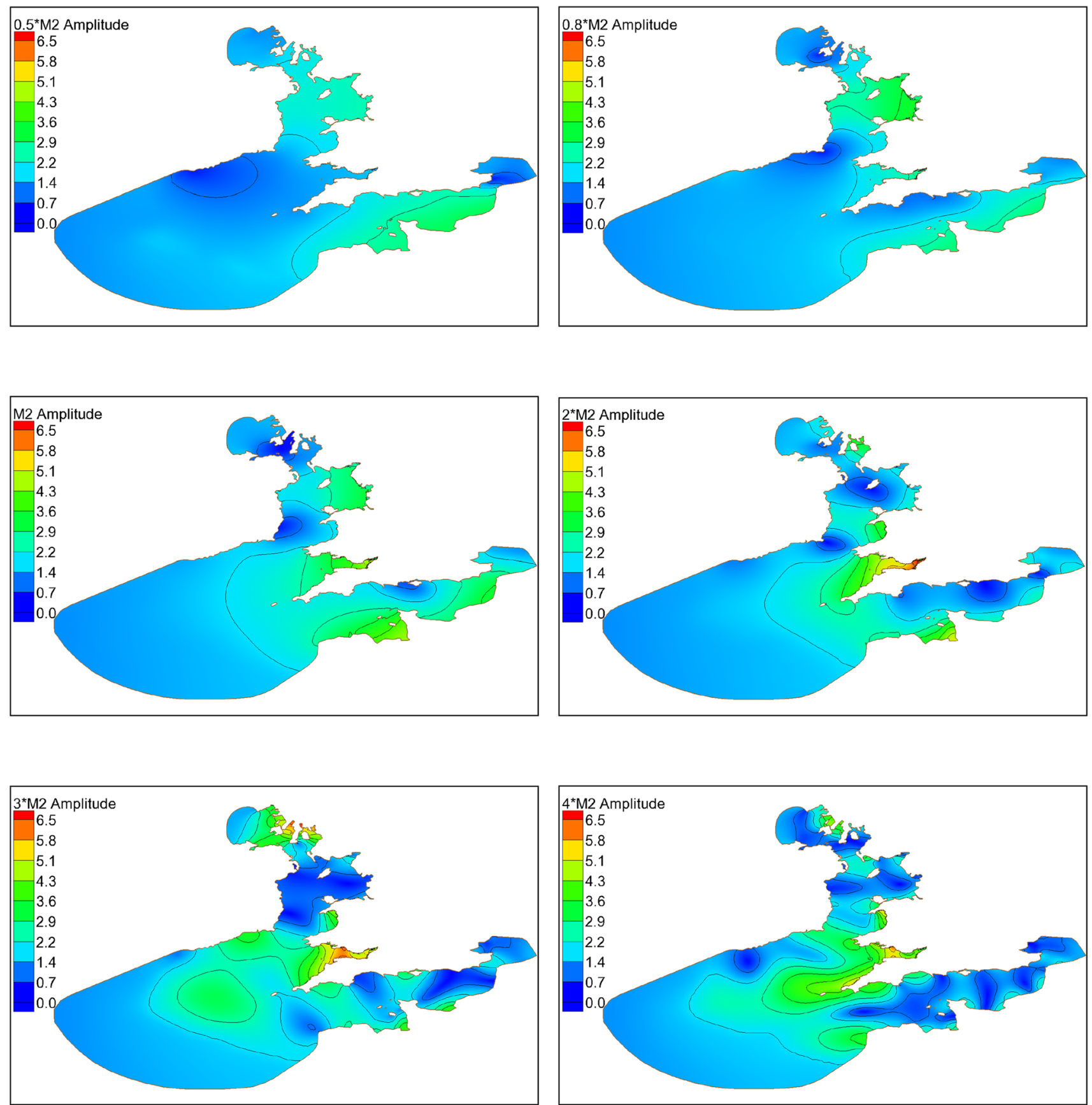

Fig. 7 Co-tidal amplitude contours (m): $0.5 M_{2}$ (top-left); $0.8 M_{2}$ (top-right); $M_{2}$ (middle-left); $2 M_{2}$ (middle-right); $3 M_{2}$ (bottom-left) and $4 M_{2}$ (bottom-right) over the model domain

The response of the channel to the barrage under normal operation is shown in Figs. 9 and 10 shows the co-tidal charts for cases with varying driving frequencies. If the barrage was shortening the effective length of the channel then it would be expected that the resonances, especially those within the channel itself, would be shifted. It is slightly surprising that the resonant peaks in the channel do not appear to shift significantly with the barrage present (the second resonance peak is only shifted by approximately $12.6 \mathrm{~min}$ ). On the ocean side of the barrage there is almost no change to the resonant frequencies. For the higher frequencies, there appears to be a reduction in the 

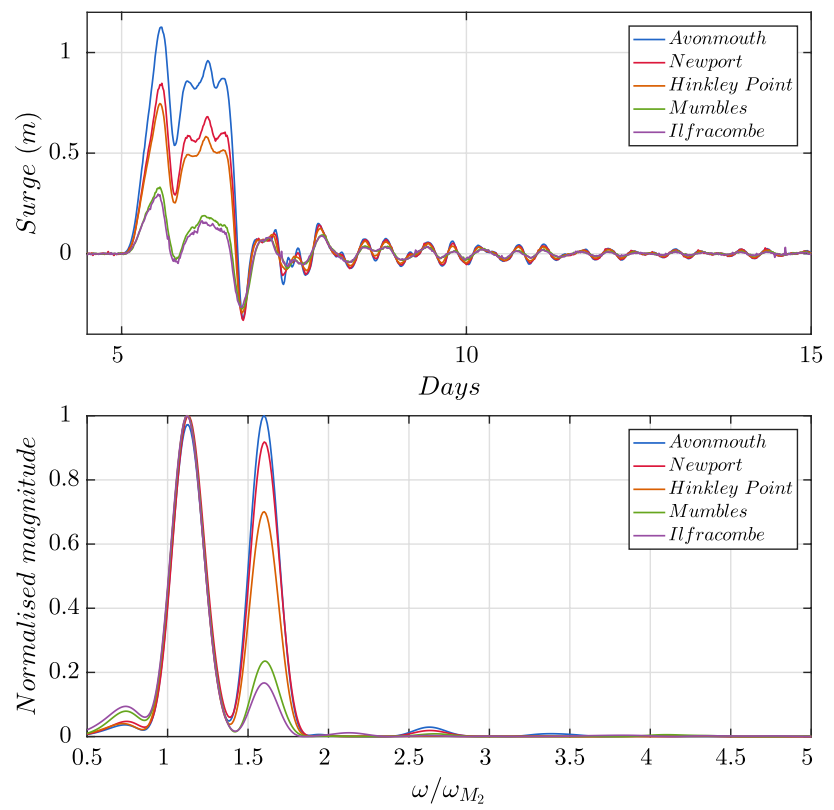

Fig. 8 Disturbance analysis for a west wind within the Bristol Channel for the case without a barrage at five measurements stations: wind-driven surge (top); Normalised magnitude spectrum (bottom)

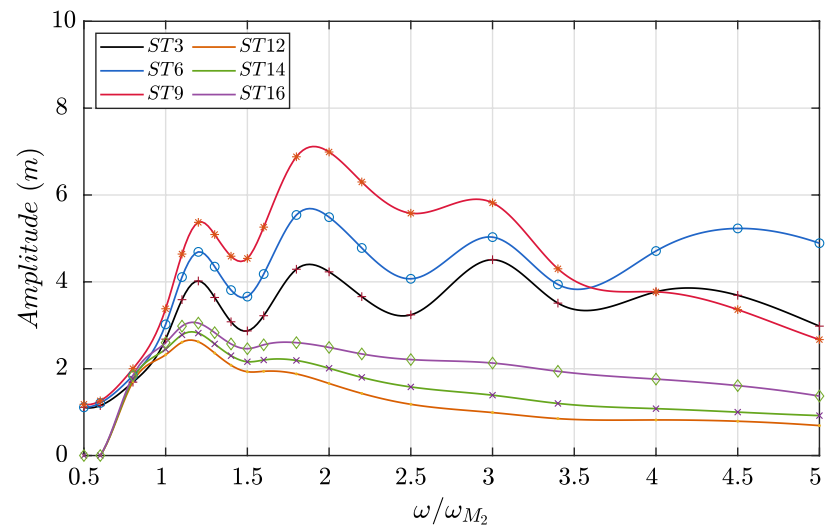

Fig. 9 Resonance responses for the barrage in normal operation case along the channel

damping. This is surprising since it would be expected that a barrage would extract energy although the barrage would also reduce the energy lost in friction in the shallower areas of the channel.

Figure 11 presents the amplitude of the tide at three stations along the Bristol Channel for different operating strategies and for different tidal frequencies. At the mouth of the channel, the barrage causes negligible change when operated normally and very small changes across the whole spectrum for the case in which there is no flow through the barrage.

Within the channel, and particularly near the barrage, the barrage leads to very little change at the natural $M_{2}$ tidal frequency. This is in keeping with other studies which suggest the Severn Barrage would lead to a surprisingly small change in the tidal range on the ocean side of the barrage (Xia et al. 2010a). The reason for this is presumably that the resonant mode close to the semi-diurnal period is associated with the whole Celtic Sea/Bristol Channel system (see Sect. 4) and so modifying the dynamics in the Bristol Channel itself has a rather small impact. However, for higher excitation frequencies, there is considerable change-particularly for the case where the barrage is completely shut. At the barrage itself, the amplitude of the tide increases considerably when excited by a higher frequency.

Our analysis does suggest some resonances near to the barrage close to the $2=\omega / \omega_{2}$ frequency. This is close to the frequency of the $M_{4}$ tide. This constituent usually arises from the $M_{2}$ tide interacting with the varying cross-section of the channel. It is seen as important for sediment transport (Pingree and Griffiths 1979) and, therefore, impacts on the environment. Given this constituent is locally generated rather than driven by external forcing it is hard to directly assess the implications of this peak. We return to this in the discussion.

\subsection{Impact of lagoon implementation}

We now briefly consider the impact of the Swansea lagoon on resonance. This is a small deployment compared to a barrage and thus one would expect the change to the large scale tidal dynamics to be small. Thus, we only consider the extreme case where the lagoon is closed as this will be a limiting case for the amount of change that might be observed.

Figure 12 presents the response curves for the lagoon and barrage implementation, respectively. The response of the estuary with the lagoon present is nearly identical to the natural case. This result is in keeping with expectations that the Swansea Lagoon is too small to make major changes to the large scale hydrodynamics of the region. There will, of course, be significant local changes.

\section{Discussion}

The scope of the present paper is only to consider the how the resonance characteristics of the Bristol Channel/ Severn Estuary system are altered by a barrage. The object of this 

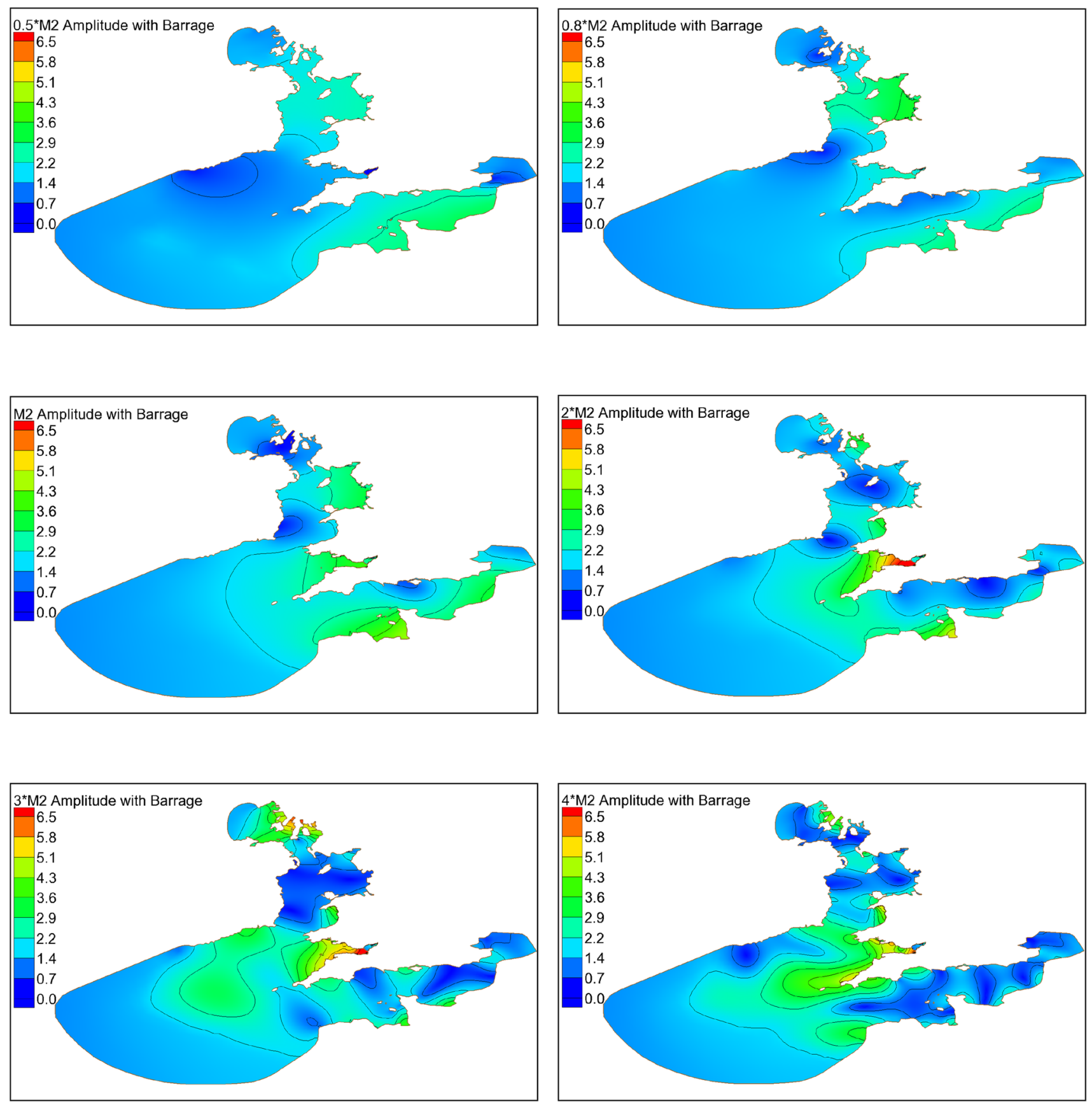

Fig. 10 Co-tidal amplitude contours (m) with barrage normally operated case: $0.5 M_{2}$ (top-left); $0.8 M_{2}$ (top-right); $M_{2}$ (middle-left); $2 M_{2}$ (middle-right); $3 M_{2}$ (bottom-left) and $4 M_{2}$ (bottom-right) over the model domain

paper is better to understand the things driving the changes to the hydrodynamics, rather than looking at these directly. Still more, we do not look at things which are, in turn, driven by the hydrodynamics such as sediment transport, flushing and circulation, etc. which will be crucial to assessing the impact of any barrage scheme. 

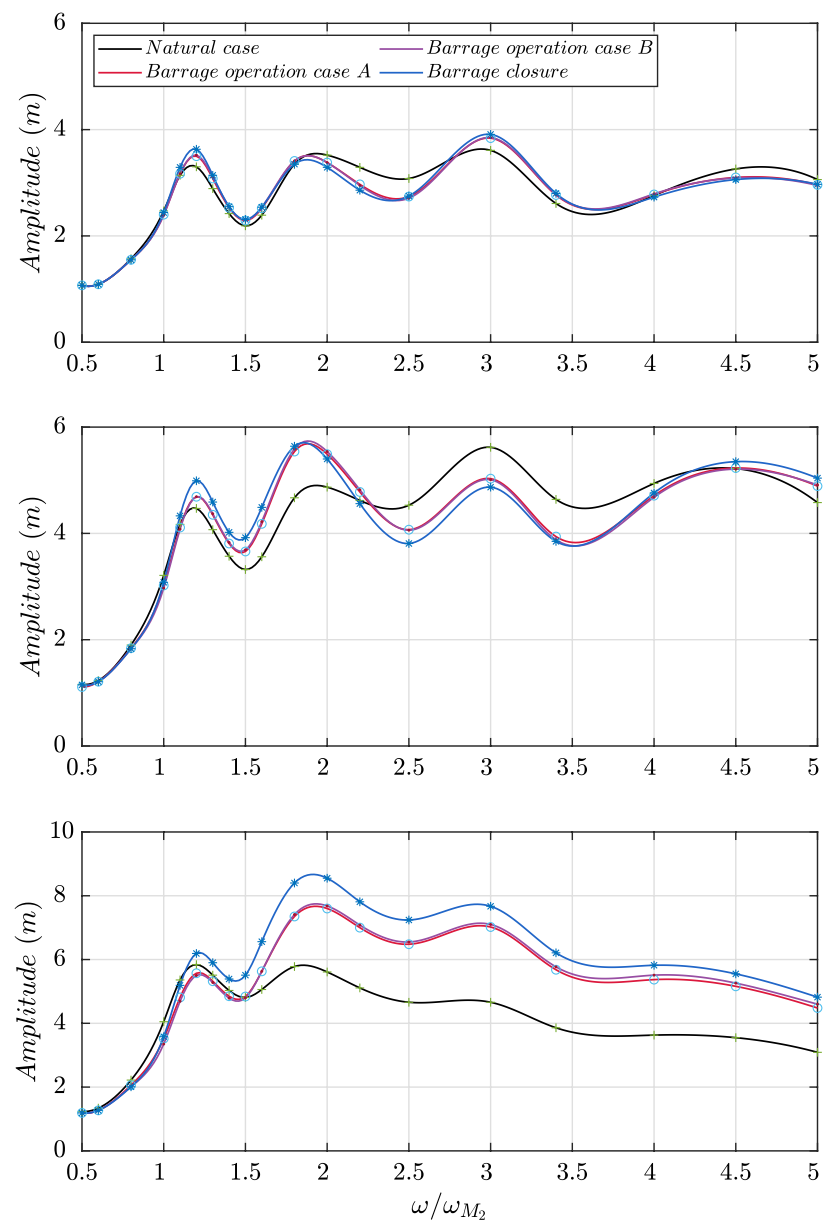

Fig. 11 Resonance responses of the barrage operation cases comparisons: responses at the entrance, $51.24^{\circ} \mathrm{N} 4.83^{\circ} \mathrm{W}$, of the channel (top); Responses at the middle, $51.41^{\circ} \mathrm{N} 3.92^{\circ} \mathrm{W}$, of the channel (middle); Responses at the inner (barrage site), $51.32^{\circ} \mathrm{N} 3.17^{\circ} \mathrm{W}$, of the channel (bottom)

Around the semi-diurnal frequencies (i.e. those of the dominant $M_{2}$ and $S_{2}$ constituents), we see perhaps surprisingly little change. This perhaps explains why changes to the tidal hydrodynamics outside the Bristol Channel are predicted to be relatively small (except where very simplistic models of energy extraction are used). Interestingly we do see a resonance around twice the semi-diurnal frequency. This is close to the $M_{4}$ frequency which is significant environmentally for its role in sediment transport. The $M_{4}$ constituent is (primarily) locally generated within the estuary rather than being an incoming tidal wave from outside. Our methodology looks primarily at the amplification of incoming waves and so caution should be used in applying its conclusions to the $M_{4}$ constituent directly. Nevertheless, our method does suggest that resonant amplification of this constituent is possible when a barrage is present.
The accuracy of the results in this paper are of course dependent on the modelling assumptions and the imposed boundary conditions. The shallow water equations are generally a good descriptor of the large scale tidal physics as investigated herein. Key boundary conditions are the bathymetry and bed friction. A good insight into the sensitivity of these on the calculation was carried out in the preliminary work by Gao and Adcock (2017) and Gao (2017). Based on Gao's analysis, the basic results presented here are robust and would only be slightly modified by errors in these values. Furthermore, of course, both bathymetry and bed friction can vary over time, particularly in the shallower parts of the estuary and the installation of a barrage would alter the sediment transport and hence the morphology of the estuary.

\section{Conclusions}

The tidal resonance characteristics of the Bristol Channel suggests a coupled resonance system which is, perhaps surprisingly, complex. Adding a barrage structure to this system increases this complexity further. However, the Severn Barrage appears to make little difference to the resonant response for frequencies close to the dominant semi-diurnal frequencies. Given that changes to the resonant response are a potential cause of significant changes to the large scale hydrodynamics this is reassuring. These findings partially explain why changes to the tidal hydrodynamics are predicted to be relatively localised to a Severn Barrage, despite the magnitude of such a structure. If a barrage were to be installed in the Bay of Fundy, which has a resonant period slightly larger than that of the semi-diurnal tide, it is probable that there would be far more significant changes than we have found in this study.

Acknowledgements QM was supported by the Chinese Scholarship Council towards this work. We thank Dr Sena Serhadlıoğlu who did important preliminary work for this study.

Open Access This article is licensed under a Creative Commons Attribution 4.0 International License, which permits use, sharing, adaptation, distribution and reproduction in any medium or format, as long as you give appropriate credit to the original author(s) and the source, provide a link to the Creative Commons licence, and indicate if changes were made. The images or other third party material in this article are included in the article's Creative Commons licence, unless indicated otherwise in a credit line to the material. If material is not included in the article's Creative Commons licence and your intended use is not permitted by statutory regulation or exceeds the permitted use, you will need to obtain permission directly from the copyright holder. To view a copy of this licence, visit http://creativecommons.org/licenses/by/4.0/. 
Fig. 12 Resonance responses of the lagoon cases comparisons: Responses at the entrance, $51.24^{\circ} \mathrm{N} 4.83^{\circ} \mathrm{W}$, of the channel (top-left); Responses at the middle, $51.41^{\circ} \mathrm{N} 3.92^{\circ}$ $\mathrm{W}$, of the channel (top-left); Responses at the Severn Barrage site, $51.32^{\circ} \mathrm{N} 3.17^{\circ} \mathrm{W}$, (bottom-left); Responses at the Swansea Lagoon site, $51.54^{\circ} \mathrm{N}$ $3.92^{\circ} \mathrm{W}$, (bottom-right)
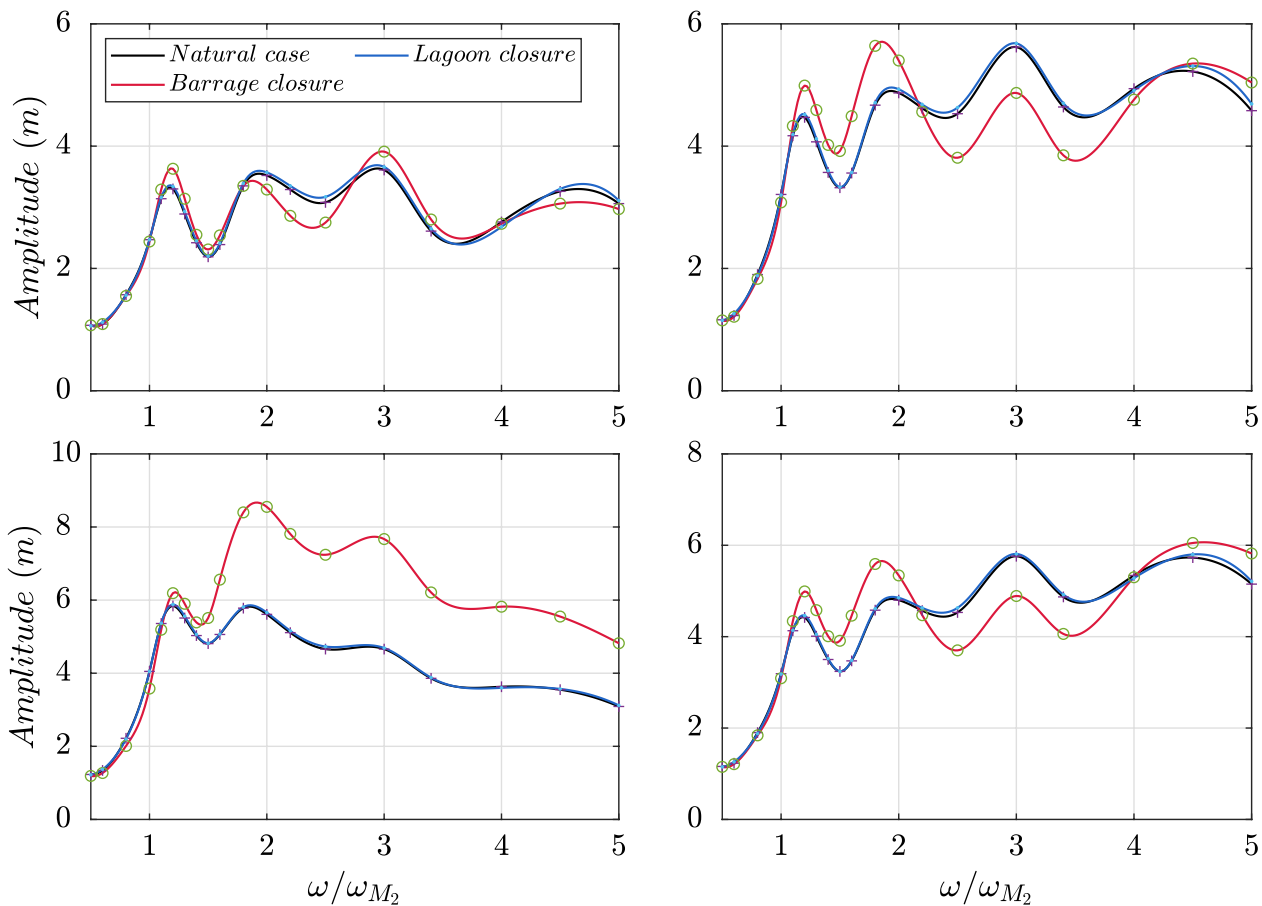

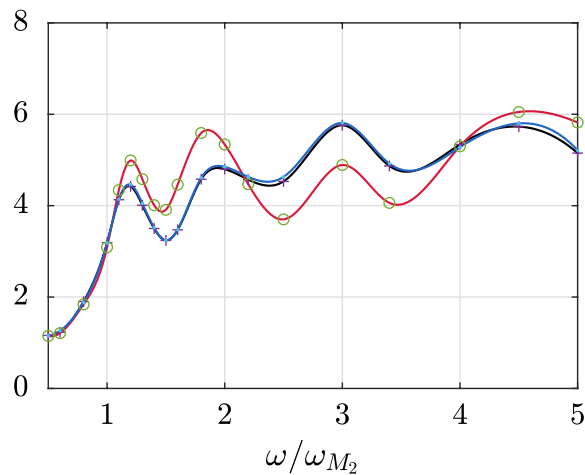

\section{References}

Adcock TAA, Draper S (2014) On the tidal stream resource of two headland sites in the English channel: Portland Bill and Isle of Wight. Proc Int Conf Offshore Mech Arctic Eng 9A:1-10

Adcock TAA, Draper S, Houlsby GT, Borthwick AGL, Serhadlıŏlu S (2013) The available power from tidal stream turbines in the Pentland Firth. Proc R Soc A Math Phys Eng Sci 469(2157):20130

Adcock TAA, Draper S, Houlsby GT, Borthwick AGL, Serhadlığlu S (2014) Tidal stream power in the Pentland Firth-long-term variability, multiple constituents and capacity factor. Proc Inst Mech Eng Part A J Power Energy 228(8):854-861

Arbic BK, Garrett C (2010) A coupled oscillator model of shelf and ocean tides. Cont Shelf Res 30(6):564-574

Arbic BK, Karsten RH, Garrett C (2009) On tidal resonance in the global ocean and the back-effect of coastal tides upon open-ocean tides. Atmos Ocean 47(4):239-266

Baker C (1991) Tidal Power. Institution of Electrical Engineers, London, UK

Bondi H (1981) Tidal power from the Severn Estuary: report to the Secretary of State for Energy. Tech. rep. Department of Energy, Severn Barrage Committee, London, UK

Bourban S, Couch S, Baldock A, Cheeseman S (2014) Coastal shelf model of northern European water to inform tidal power industry decisions: SMARTtide. Underw Technol 1(32):15-26

Bunya S, Kubatko EJ, Westerink JJ, Dawson C (2009) A wetting and drying treatment for the Runge-Kutta discontinuous Galerkin solution to the shallow water equations. Comput Methods Appl Mech Eng 198(17-20):1548-1562

Cui X, Fang G, Wu D (2019) Tidal resonance in the Gulf of Thailand. Ocean Sci 15(2):321-331

Fong SW, Heaps NS (1978) Note on quarter wave tidal resonance in the Bristol Channel. Tech. rep, Institute of Oceanographic Sciences

Gao C (2017) Analysis of storm surge and tidal resonance in the Bristol channel. MSc thesis, University of Oxford
Gao C, Adcock TAA (2017) On the tidal resonance of the Bristol Channel. Int J Offshore Polar Eng 27(2): 1

Garrett C (1972) Tidal resonance in the Bay of Fundy and Gulf of Maine. Nature 238(5365):441

Godin G (1993) On tidal resonance. Cont Shelf Res 13(1):89-107

Heath RA (1981) Resonant period and Q of the Celtic Sea and Bristol Channel. Estuar Coast Shelf Sci 12(3):291-301

Hendry C (2016) The role of tidal lagoons. Tech. rep, UK Government

Kirby R, Shaw TL (2005) Severn barrage, UK-environmental reappraisal. Proc Inst Civ Eng Eng Sustain 158(1):31-39

Kubatko EJ, Westerink JJ, Dawson C (2006) hp discontinuous Galerkin methods for advection dominated problems in shallow water flow. Comput Methods Appl Mech Eng 196(1-3):437-451

Liang D, Xia J, Falconer RA, Zhang J (2014) Study on tidal resonance in Severn Estuary and Bristol Channel. Coast Eng J 56(01):1450,002

Ma Q, Moreira TM, Adcock TAA (2019a) Impact of the Swansea Bay lagoon on storm surges in the Bristol Channel. In: Proceedings of the 38th International Conference on Ocean, Offshore and Arctic Engineering, Glasgow, UK

Ma Q, Moreira TM, Adcock TAA (2019b) The impact of a tidal barrage on coastal flooding due to storm surge in the Severn Estuary. J Ocean Eng Mar Energy 5:217-226

Mulamba T, Bacopoulos P, Kubatko EJ, Pinto GF (2019) Sea-level rise impacts on longitudinal salinity for a low-gradient estuarine system. Clim Change 1:1-18

Neill S, Angeloudis A, Robins P, Walkington I, Ward S, Masters I, Lewis M, Piano M, Avdis A, Piggott M, Aggidis G, Evans P, Adcock TAA, Židonis A, Ahmadian R, Falconer R (2018) Tidal range energy resource and optimization: past perspectives and future challenges. Renew Energy 127:763-778

Osment J, Halstead P, Pontee N (2011) Reassessing the severn barrage: Operational modes and their impacts. In press: Coastal management 2011 innovative coastal zone management: sustainable engineering for a dynamic coast 
Pingree RD, Griffiths D (1979) Sand transport paths around the british isles resulting from $\mathrm{m} 2$ and $\mathrm{m} 4$ tidal interactions. J Mar Biol Assoc UK 59(2):497-513

Prandle D (1984) Simple theory for designing tidal power schemes. Adv Water Resour 7(1):21-27

Pugh D (1996) Tides, surges and mean sea-level. Wiley, Swindon

Schnabl AM, Moreira TM, Wood D, Kubatko EJ, Houlsby GT, McAdam RA, Adcock TAA (2019) Implementation of tidal stream turbines and tidal Barrage structures in DG-SWEM. In: Proceedings of the 38th international conference on ocean, offshore and arctic engineering, Glasgow, UK

Serhadlığlu S (2014) Tidal stream resource assessment of the Anglesey Skerries and the Bristol Channel. DPhil Thesis, University of Oxford

Serhadlıŏlu S, Adcock TAA, Houlsby GT, Draper S, Borthwick AGL (2013) Tidal stream energy resource assessment of the Anglesey Skerries. Int J Mar Energy 3:e98-e111

Sutherland G, Garrett C, Foreman M (2005) Tidal resonance in Juan de Fuca Strait and the Strait of Georgia. J Phys Oceanogr 35(7):1279-1286

Ward SL, Green JAM, Pelling HE (2012) Tides, sea-level rise and tidal power extraction on the european shelf. Ocean Dyn 62(8):1153-1167
Waters S, Aggidis G (2016) A world first: Swansea bay tidal lagoon in review. Renew Sustain Energy Rev 56:916-921

Westerink JJ, Luettich RA, Feyen JC, Atkinson JH, Dawson C, Roberts HJ, Powell MD, Dunion JP, Kubatko EJ, Pourtaheri H (2008) a basin- to channel-scale unstructured grid hurricane storm surge model applied to Southern Louisiana. Mon Weather Rev 136(3):833-864

Xia J, Falconer RA, Lin B (2010a) Hydrodynamic impact of a tidal barrage in the Severn Estuary, UK. Renew Energy 35(7):1455-1468

Xia J, Falconer RA, Lin B (2010b) Impact of different operating modes for a Severn Barrage on the tidal power and flood inundation in the Severn Estuary, UK. Appl Energy 87(7):2374-2391

Publisher's Note Springer Nature remains neutral with regard to jurisdictional claims in published maps and institutional affiliations. 